\title{
Factors associated with contracted services of Chinese family doctors from the perspective of medical staff and consumers: a cross-sectional study
}

Huanyan Wang ${ }^{1,2+}$, Lei Shi ${ }^{1+}$, Xuanye Han ${ }^{3+}$, Jinchan Zhang ${ }^{4}$, Yuanshuo Ma ${ }^{1}$, Xi Yang ${ }^{1}$, Ming Liu ${ }^{1}$, Lihua Fan ${ }^{1 *}$ and Fengge Lou $^{5^{*}}$

\begin{abstract}
Background: The family doctor system has developed rapidly all over the world, and in the past few years, China has actively explored family doctor-type contracted services. This study aimed to explore the related factors of Contracted Family Doctors Services (CFDS) from the perspectives of medical staff and consumers, and to provide a stronger basis for the development and promotion of CFDS.

Methods: A combination of quantitative and qualitative methods were used in this study. A self-reported questionnaire was designed through a literature analysis, group discussions, expert consultations and a preinvestigation, and conducted among community health service providers in 12 community health service centres across four provinces of China. A total of 389 participants participated, and 320 valid questionnaires were obtained, with an effective response rate of $82.3 \%$. A total of 36 consumers participated in in-depth interviews, and the effective rate was $100.0 \%$. An exploratory factor analysis, a confirmatory factor analysis, inductive methods, and expert consultations were used to analyse the related factors of CFDS.

Results: The related factors of CFDS from the perspectives of medical staff were divided into four dimensions, with the following weighting coefficients: national government factors (31.9\%), community health service agency factors (24.7\%), consumer-related factors (22.6\%), and contracted doctor-related factors (20.8\%). The related factors of CFDS from the perspectives of consumers were divided into four dimensions, with the following frequency sequence: national government factors, contract doctor-related factors, community health service agency factors, and consumers-related factors. National government factors played an important role in CFDS from the perspectives of medical staff and consumers.

Conclusions: The related factors of CFDS were the same from the perspective of medical staff and consumers, but the weight of each factor was different. The development of CFDS is inseparable from the support of policies. It is suggested that the government should strengthen the publicity of CFDS, expand the coverage, introduce personalised contract programs that meet the needs of different groups, and promote the rapid development of CFDS.
\end{abstract}

Keywords: Family doctors, Related factors, Contracted services, Patients

\footnotetext{
* Correspondence: Ihuafan@126.com; Ifgycy@163.com

†Huanyan Wang, Lei Shi and Xuanye Han contributed equally to this work.

${ }^{1}$ Department of Health Management, School of Health Management, Harbin

Medical University, No.157 Baojian Road, Nangang District, Harbin 150081,

China

${ }^{5}$ Department of Public Health Research, School of Public Health, Qiqihar

Medical University, Qiqihar, Heilongjiang, China

Full list of author information is available at the end of the article
}

C The Author(s). 2019 Open Access This article is distributed under the terms of the Creative Commons Attribution 4.0 International License (http://creativecommons.org/licenses/by/4.0/), which permits unrestricted use, distribution, and reproduction in any medium, provided you give appropriate credit to the original author(s) and the source, provide a link to the Creative Commons license, and indicate if changes were made. The Creative Commons Public Domain Dedication waiver (http://creativecommons.org/publicdomain/zero/1.0/) applies to the data made available in this article, unless otherwise stated. 


\section{Background}

The family doctor system, as an important policy measure to realize the Alma-Ata Declaration's grand goal of primary health care for all, has gained rapid ground worldwide [1]. According to a World Health Organization report, the proportion of all patients with diseases requiring specialized medical treatment was only about $5 \%$, and more than $90 \%$ of health problems could be effectively solved by professionally trained general practitioners [2]. The role of general practitioners/ family doctors, according to the World Organization of Family Doctors, is to provide comprehensive health care services and to arrange for other health professionals to provide related services when necessary [3].

The family doctor system has been implemented in more than 50 countries and regions and has achieved gratifying results in various respects, which has attracted the attention of governments and medical circles [4]. There exist obvious differences in the specific service modes and operating mechanisms in various countries. Moreover, there is no doubt that the family doctor system plays an important role in medical and health service systems. The family doctor system originated in the United States in the 1960s [5], when the government integrated health management into the community general practitioner service model [6]. At the same time, active follow-up observations were performed on patients with chronic diseases and during the rehabilitation period [6].

In the U.K., the National Health Service was established in 1948 and adopted the national management model, which requires citizens to register with their family doctors and sign contracts with them [7]. Cuba established the family doctor program, in which a family physician and at least one nurse were each responsible for providing primary disease prevention and medical treatment services to 120-150 families [8]. The family doctor system in Denmark is a form of health care developed from the private doctor system, and each family doctor is responsible for a maximum of 1780 health care-registered patients /consumers [9].

However, in China, the idea of 'family doctors' was introduced in the 1980s, when 'family doctor-type contracted services' were proposed. In 2003, the Chinese government put forward the family doctor system as the goal of the development of community health services so that everyone can benefit from family doctor services [10]. The promulgation of the Guiding Opinions of the State Council on the Establishment of the General Practitioner System in 2011 indicates that the establishment of the family doctor system has become national strategy [11]. Subsequently, the training objectives, methods, and contents, and the ability requirements of general practitioners were further clarified [12]. The Guideline on Promoting Contracted Family Doctor Services was issued to accelerate family doctor contract services [12]. To improve quality and efficiency the National Health and Family Planning Commission also pointed out that the work of family doctors has changed [13], and the contracted family doctor services (CFDS) have been promoted in a systematic way across China.

In recent years, China has been exploring the implementation of family doctor-type contracted services. At present, five typical contracted service models have been formed; for example, the ' $1+1+1$ ' contracted service model in Shanghai [14], 'basic package + personalized package' contracted service model in Yancheng, Jiangsu Province [15], 'integrated Medical treatment and nursing care system' contracted service model in Hangzhou, Zhejiang Province [16], 'co-management of doctors of three kinds' contracted service model in Xiamen, Fujian Province [17], and 'capitation prepayment' contracted service model in Dingyuan, Anhui Province [15].

The research on family doctors in China has mainly focused on the significance and difficulties of establishing a family doctors system, or it has explored the policy effects of family doctors in terms of service utilization, management of non-communicable diseases, medical expenses, and satisfaction [18-21]. Some researchers have also noticed the importance of establishing stable relationships with family doctors, as well as contract status and contract behaviour [22, 23]. Wenjuan and colleagues studied the primary health service capacity in Western China from different doctor and patient perspectives, and found that coordination is the weakest component of the primary health service ability [24]. A crosssectional study indicated that the awareness rate of residents on CFDS is $71.58 \%$, the contracted rate of family doctors is $50.43 \%$, and the demand for contracted services with residents is high in Zhejiang Province [25]. Moreover, another study found that contract behaviour was positively correlated with awareness of family doctors services [23]. Previous studies on CFDS in China focused on the allocation of work resources, significance and difficulties of establishing family doctor system, optimization of contracted service content, exploration of team performance appraisal mechanisms, change of payment mode of medical insurance for contracted services, willingness and satisfaction of contracted services, and work competency and stability [14, 26-29]. Relevant scholars have also proposed some suggestions and directions for the development of CFDS and analysed specific CFDS factors [3, 30].

The 'Healthy China 2030' plan was released by the central government in 2016 and is an important longterm national strategic plan. The family doctor service has been regarded as an important tool to achieve Health China 2030 [31] alongside 'China improves health services for senior citizens' (this project aims to 
prevent and control chronic diseases and promote good health among senior citizens, and calls on family doctors to play a more important role) [32], and a circular on completing CFDS (which aims to improve the quality of CFDS and promote the quality and efficiency of CFDS) was published in 2019 [33]. Improving patients/consumers' willingness to sign contracts with family doctors is a recent policy focus for the government; however, few studies have examined the factors relating to why families sign up to these services and the proportion of policies that include these factors from the perspective of medical staff and patients/consumers, which are worth exploring. Therefore, this study explored the factors associated with CFDS from the perspectives of community health service providers, administrators, medical staff, and patients/consumers, which can help to improve the contracting rate of family doctors, promote the health of consumers, and provide a basis for the government and health administration to formulate policies for CFDS.

\section{Methods}

\section{Study design and participants}

A cross-sectional survey was used to select 12 community health service centres in four regions in Zhejiang, Anhui, Beijing, and Shanghai provinces in a typical area survey. First, a typical city with CFDS in each province was purposively selected. Then, according to the development of CFDS (high, medium, and low), three community health service centres were selected using purposive sampling. The cluster sampling method was used to conduct a questionnaire survey with the directors of the community health service centres, the CFDS team from the community health service agencies, and the administrative staff. Moreover, convenience sampling was used to conduct in-depth interviews with patients/ consumers in the same regions. This study mainly combined qualitative (interviews) and quantitative (questionnaire) methods, although only at the methodological level. A questionnaire survey was used to explore the related factors of CFDS from the perspective of medical staff, and interviews were conducted to explore the related factors of CFDS from the perspective of the patients /consumers.

\section{Data collection}

Data were collected from July to September 2017. The respondents completed an anonymous questionnaire after providing informed consent, and a total of 389 questionnaires were distributed. While all of them were returned, 320 questionnaires were valid, and so the total effective rate was $82.3 \%$. The reasons for the elimination of questionnaires included missing data or incomplete questionnaires, multiple omissions, and multiple choices.
We interviewed three patients/consumers in each community health service centre. A total of 36 patients/ consumers were interviewed, and the total effective rate was $100.0 \%$.

\section{Questionnaire}

The questionnaire was designed and developed in this study based on the following steps. First, we attempted to select as many items as possible by searching the relevant literature [34, 35]. Next, five experts (including health service management experts, public health experts, and contracted services researchers) were consulted to revise and improve the questionnaire. Finally, a pilot study was conducted at four community health service centres (120 responses were not included in the final data analysis), and the questionnaire was further refined and finalized (Cronbach's $\alpha$ was 0.865 ). The final questionnaire comprised the following sections (shown in the Additional file 1):

1. Sociodemographic information (including gender, age, education level, and professional title, etc.).

2. The related factors of CFDS, including 29 items. Using a five-point Likert scale, each item was divided into five levels (very important, important, neutral, unimportant, and very unimportant) according to the influence degree. The participants rated each item according to their own experiences.

\section{Data analysis}

Data were analysed using IBM SPSS Statistics 20.0 and AMOS 21.0, and descriptive statistics were used to analyse the demographic characteristics of participation in community health service agencies. Factor analysis (both exploratory and confirmatory factor analyses) was used to determine the related factors of CFDS [36, 37]. Data is suitable for an exploratory factor analysis if the Kaiser-Meyer-Olkin value is greater than 0.7. The number of factors can be assumed beforehand according to the actual conditions, or the number of dimensions can be determined according to the criterion of eigenvalues greater than 1 or by examining the scree plot. The principal components method was chosen to extract the common factors. Items were excluded according to the following criteria: a factor loading of $<0.40$, high loadings on multiple factors, and a factor with less than three items included. Orthogonal rotation was used to determine simple structure, and the method of calculating factor weights was as follows: $\omega i=\left[\left(m \sum j\right) \beta i j \times e j\right] /\left[\left(n \sum\right.\right.$ i) $\left.\left(m \sum j\right) \quad \beta i j \times e j\right] ; \quad F j=\beta 1 j \times X 1+\beta 2 j \times X 2+\beta 3 j \times X 3+$ $\ldots . .+\beta n j \times X n ; F j$ is the principal component $(j=1,2, \ldots$ $\ldots \mathrm{m}), X 1, X 2, X 3, \ldots \ldots . X n$ for each index, $\beta 1 j, \beta 2 j, \beta 3 j$, ... $\beta n j$ for coefficient score of each index in principal component $F j, e j$ is used to express the equation contribution rate of $F j$. The confirmatory factor analysis model 
was considered to have a good fit when all of the path coefficients were significant at the level of $0.05 ; \mathrm{x} 2 / \mathrm{df}$ was below 5; root mean square error of approximation (RMSEA) was below 0.08; root mean square residual (RMR) was below 0.10; and the goodness of fit index (GFI), normed fit index (NFI), Tucker-Lewis incremental (TLI) fit, and comparative fit index (CFI) were $\geq 0.90$. A $p$-value of $<0.05$ was considered statistically significant.

\section{Results}

\section{Results of the in-depth interviews}

Through in-depth interviews with patients/consumers, their reasons for being more willing to accept CFDS were identified and summarized. Examples included the patients/consumers' level of understanding of CFDS; the benefits of CFDS; the concerns about one's own health; the degree of family doctors' protection of patients/consumers' privacy, cost, and process of signing a contract; satisfaction with the community; and advocacy of contracting services.

\section{Demographic characteristics of community medical staff} Of the 320 respondents, $72.2 \%$ were women, $56.6 \%$ had received an undergraduate education, and $43.4 \%$ had intermediate titles. Among the respondents, general practitioners were the main occupations, and $57.5 \%$ of the respondents had working longer than 10 years. The demographic characteristics of the medical personnel are illustrated in Table 1.

Analysis of the related factors CFDS.

\section{Exploratory factor analysis}

The Kaiser-Meyer-Olkin value was 0.836 , which demonstrated that the data could be used for the factor analysis (if the Kaiser-Meyer-Olkin value is close to 1, the variable group is suitable for a factor analysis).

After completing the orthogonal rotation of the factor loading matrix, the remaining 25 items had eigenvalues $>1$, orthogonal rotation explained the maximum amount of variance, seven factors were extracted from the system, and the cumulative variance contribution rate of 67.613\% was shown in the Additional file 2. Table 2 illustrates that 25 observational variables were classified into seven common factors. Based on the results of the group discussion among the project team members, seven factors were named according to the characteristics of the variables observed. F1 was the 'national policy factor', the combination of F2 and F3 were the 'resident factors', the combination of F4 and F5 were the 'contract doctor factors', and the combination of F6 and F7 were the 'community factors'.
Table 1 The Demographic characteristics of community medical staff $(N=320)$

\begin{tabular}{|c|c|c|}
\hline Demographic characteristics & $n$ & Percent (\%) \\
\hline \multicolumn{3}{|l|}{ Gender } \\
\hline CMale & 89 & 27.8 \\
\hline Female & 231 & 72.2 \\
\hline \multicolumn{3}{|l|}{ Age (years) } \\
\hline$\leq 30$ & 63 & 19.7 \\
\hline $31-40$ & 143 & 44.7 \\
\hline $41-50$ & 90 & 28.1 \\
\hline$>50$ & 24 & 7.5 \\
\hline \multicolumn{3}{|l|}{ Level of education } \\
\hline$<$ Bachelor & 69 & 21.6 \\
\hline Bachelor & 221 & 69.1 \\
\hline$\geq$ Master & 30 & 9.3 \\
\hline \multicolumn{3}{|l|}{ Professional title } \\
\hline No & 14 & 4.4 \\
\hline Junior & 100 & 31.3 \\
\hline Intermediate & 139 & 43.4 \\
\hline Senior & 67 & 20.9 \\
\hline \multicolumn{3}{|l|}{ Professional } \\
\hline General practitioner & 119 & 37.2 \\
\hline Chinese medicine & 25 & 7.8 \\
\hline Rehabilitation & 14 & 4.4 \\
\hline Nursing & 76 & 23.7 \\
\hline Preventive health care & 38 & 11.9 \\
\hline Administration & 24 & 7.5 \\
\hline Other & 24 & 7.5 \\
\hline \multicolumn{3}{|l|}{ Years of experience (years) } \\
\hline$<4$ & 39 & 12.2 \\
\hline $4-7$ & 47 & 14.7 \\
\hline $7-10$ & 50 & 15.6 \\
\hline$>10$ & 184 & 57.5 \\
\hline \multicolumn{3}{|l|}{ Employment form } \\
\hline Formal employee & 228 & 71.3 \\
\hline Contracted employee & 81 & 25.3 \\
\hline Temporary employee & 10 & 3.1 \\
\hline Other & 1 & 0.3 \\
\hline \multicolumn{3}{|l|}{ Monthly income (CNY) } \\
\hline$\leq 2000$ & 16 & 5.0 \\
\hline $2001-4000$ & 63 & 19.7 \\
\hline $4001-6000$ & 124 & 38.8 \\
\hline $6001-8000$ & 85 & 26.5 \\
\hline$\geq 8001$ & 32 & 10.0 \\
\hline
\end{tabular}


Table 2 Rotation component matrix

\begin{tabular}{|c|c|c|c|c|c|c|c|}
\hline \multirow[t]{2}{*}{ Items } & \multicolumn{7}{|c|}{ Component } \\
\hline & $\mathrm{F} 1$ & F2 & F3 & F4 & F5 & F6 & F7 \\
\hline X1 National financial allocations & 0.850 & & & & & & \\
\hline X2 Extent of national policy support & 0.838 & & & & & & \\
\hline X3 Extent of policy support for family doctor service & 0.801 & & & & & & \\
\hline X4 Government propaganda & 0.745 & & & & & & \\
\hline X5 Local government's investment in special funds for contracted family doctor service & 0.708 & & & & & & \\
\hline $\begin{array}{l}\text { X6 Extent of reduction in the incidence of disease because of patients/ consumers signing up for } \\
\text { this service }\end{array}$ & & 0.850 & & & & & \\
\hline X7 Extent of reduction in patients/consumers' medical costs because of signing up for this service & & 0.817 & & & & & \\
\hline $\begin{array}{l}\text { X8 Extent of improvement in the convenience of medical treatment because of signing up for this } \\
\text { service }\end{array}$ & & 0.736 & & & & & \\
\hline X9 Extent to which community patients/consumers trust their family doctors & & & 0.723 & & & & \\
\hline X10 Patients/consumers are satisfied with the contracted services & & & 0.690 & & & & \\
\hline X11 A good medical environment & & & 0.609 & & & & \\
\hline X12 Extent to which patients/ consumers respect, support, and cooperate with family doctors & & & 0.602 & & & & \\
\hline X13 Extent of contracted doctors' general medical knowledge and mastery of skills & & & & 0.857 & & & \\
\hline X14 Degree of contracted doctors' health management knowledge and skills & & & & 0.775 & & & \\
\hline X15 Extent of the increase in workload & & & & 0.585 & & & \\
\hline X16 Situation of the first diagnosis of the patients/consumers & & & & 0.488 & & & \\
\hline X17 Awareness of family physician policy & & & & & 0.790 & & \\
\hline X18 Self-working ability & & & & & 0.726 & & \\
\hline X19 Follow the family doctor's wishes & & & & & 0.706 & & \\
\hline X20 Degree of development of informatization of community medical institutions & & & & & & 0.837 & \\
\hline $\begin{array}{l}\text { X21 Completeness of the performance assessment mechanism of the family physician in the } \\
\text { community }\end{array}$ & & & & & & 0.717 & \\
\hline X22 Community medical equipment update and supplement situation & & & & & & 0.711 & \\
\hline X23 Situation that the resident gives the family doctor subsidy after signing a contract & & & & & & & 0.814 \\
\hline X24 Incentive mechanism & & & & & & & 0.683 \\
\hline X25 Recognition of work by the leadership & & & & & & & 0.541 \\
\hline
\end{tabular}

\section{Confirmatory factor analysis}

The results of the confirmatory factor analysis were as follows: the RMSEA was 0.059 , and thus was less than the 0.08 cut-off that indicates a good fit; the RMR was 0.05 ; The TLI, NFI, GFI, and CFI were 0.913, 0.902, 0.905 , and 0.917 , respectively.

\section{Results of expert consultations}

The health and family planning commission, contracted services researchers, and administrators were selected to carry out an expert consultation. The above results were modified according to their inputs, and the final versions of the predisposing factors are listed below.

In the first round of consultation, the name of each dimension in the model was modified: 'national policy factors' were revised to 'national government factors', 'resident factors' were revised to 'consumers-related factors', 'contracted doctor factors' was revised to 'contracted doctor-related factors', and 'community factors' were revised to 'community health service agency factors'.

The second round of consultation integrated the dimensions of the model. The experts deemed that the 'situation of the first diagnosis of the patients/consumers' should be incorporated into the residentrelated factors dimension rather than contracted doctor-related factors.

\section{The final determinants of the CFDS factors}

The final determinants of the CFDS factors are shown in Table 3. The related CFDS factors from the perspective of medical staff were divided into four dimensions and 25 items. The four dimensions were named national government factors, community health service agency factors, consumer-related factors, and contracted doctor-related factors, respectively. 
Table 3 The factors of contracted family doctors services

\begin{tabular}{|c|c|}
\hline Dimensions & Component \\
\hline \multirow{5}{*}{$\begin{array}{l}\text { 1. National government } \\
\text { factors }\end{array}$} & 1.1 National financial allocations \\
\hline & 1.2 Extent of national policy support \\
\hline & $\begin{array}{l}1.3 \text { Extent of policy support for family } \\
\text { doctor service }\end{array}$ \\
\hline & 1.4 Government propaganda \\
\hline & $\begin{array}{l}\text { 1.5Local government's investment in special } \\
\text { funds for contracted family doctor service }\end{array}$ \\
\hline \multirow[t]{6}{*}{$\begin{array}{l}\text { 2. Community health } \\
\text { service agency factors }\end{array}$} & $\begin{array}{l}\text { 2.1 Degree of development of } \\
\text { informatization of community medical } \\
\text { institutions }\end{array}$ \\
\hline & $\begin{array}{l}\text { 2.2 Completeness of the performance } \\
\text { assessment mechanism of the family } \\
\text { physician in the community }\end{array}$ \\
\hline & $\begin{array}{l}2.3 \text { Community medical equipment update } \\
\text { and supplement situation }\end{array}$ \\
\hline & $\begin{array}{l}\text { 2.4The situation that the resident gives the } \\
\text { family doctor subsidy after signing a } \\
\text { contract }\end{array}$ \\
\hline & 2.5 Incentive mechanism \\
\hline & 2.6Recognition of work by the leadership \\
\hline \multirow[t]{8}{*}{$\begin{array}{l}\text { 3. Consumers-related } \\
\text { factors }\end{array}$} & $\begin{array}{l}\text { 3.1 Extent of reduction in the incidence of } \\
\text { disease because of patients/consumers } \\
\text { signing up for this service }\end{array}$ \\
\hline & $\begin{array}{l}\text { 3.2 Extent of reduction in patients/ } \\
\text { consumers' medical costs because of } \\
\text { signing up for this service }\end{array}$ \\
\hline & $\begin{array}{l}\text { 3.3 Extent of improvement in the } \\
\text { convenience of medical treatment because } \\
\text { of signing up for this service }\end{array}$ \\
\hline & $\begin{array}{l}\text { 3.4 Extent to which community patients/ } \\
\text { consumers trust their family doctors }\end{array}$ \\
\hline & $\begin{array}{l}\text { 3.5 Patients/consumers are satisfied with } \\
\text { the contracted services }\end{array}$ \\
\hline & 3.6 A good medical environment \\
\hline & $\begin{array}{l}3.7 \text { Extent to which patients/consumers } \\
\text { respect, support, and cooperate with family } \\
\text { doctors }\end{array}$ \\
\hline & $\begin{array}{l}\text { 3.8 Situation of the first diagnosis of the } \\
\text { patients/ consumers }\end{array}$ \\
\hline \multirow{6}{*}{$\begin{array}{l}\text { 4. Contracted doctor- } \\
\text { related factors }\end{array}$} & 4.1 Extent of the increase in workload \\
\hline & $\begin{array}{l}\text { 4.2 Mastery knowledge and skills of general } \\
\text { practice of contracted doctors }\end{array}$ \\
\hline & $\begin{array}{l}\text { 4.3Mastery knowledge and skills of health } \\
\text { management of contracted doctors }\end{array}$ \\
\hline & 4.4 Awareness of family doctors policy \\
\hline & 4.5 Self-working ability \\
\hline & 4.6 To be the wishes of a family doctor \\
\hline
\end{tabular}

Calculation of the factor weights of related CFDS factors from the perspective of medical staff and consumers The cumulative variance contribution rate of F1-F7 was 67.613\% (shown in the Additional file 2). The weighted mean of the variance contribution rate of each factor was calculated, and the evaluation formula of the comprehensive score was obtained: $F=(0.302 \mathrm{~F} 1+0.107 \mathrm{~F} 2+0.0701 \mathrm{~F} 3+$ $0.0571 \mathrm{~F} 4+0.0531 \mathrm{~F} 5+0.0458 \mathrm{~F} 6+0.0406 \mathrm{~F} 7) / 0.676$. Indicator weight $=$ composite score/model coefficient.

Based on the above results, we merged similar factors into four dimensions. Finally, the weight coefficients of the common factors were $0.319,0.247,0.226$, and 0.208 , respectively (see Table 4 for specific details).

Table 5 illustrated that the frequency and ranking of related CFDS factors from the perspective of the consumers. The keywords extracted from the interviews were counted and we found that the frequency sequence of related CFDS factors from the perspective of consumers were as follows: national government factors, contract doctor-related factors, community health service agency factors, and consumers-related factors.

\section{Discussion}

Comparing the factors associated with CFDS from the perspectives of patients and of medical staff, we found that the factors of national policy and community health service agency are two important common related factors of CFDS based on the results of interviews, surveys and expert consultations.

The results demonstrated that the national government factor is the main trigger that affected CFDS the most. The government, as the dominant force in the establishment and operation of contracted services, is obligated to ensure the smooth progress of CFDS, to guarantee the fairness and accessibility of services, and conduct the contracted service's policy.

The government has developed universal health insurance coverage, basic public health service plans, and the national essential drug system, all of which have improved access to and affordability of primary health care [38]. From the perspective of the national government, it is very important to increase financial support for primary health facilities. At the same time, the government should play its part in macroeconomic regulation and control, and combine related departments, such as finance and social security to increase support for inclination to support of community medical institutions, and guide the insured personnel to give priority to primary clinics. In addition, public health services such as health management and health education conducted by family

Table 4 Weight and ranking of related factors for family doctor contracted services from the perspective of medical staff

\begin{tabular}{lll}
\hline Sequence & Factor & Weight (\%) \\
\hline 1 & National government factors & 31.9 \\
2 & Community health service agency factors & 24.7 \\
3 & Consumers-related factors & 22.6 \\
4 & Contract doctor- related factors & 20.8 \\
\hline
\end{tabular}


Table 5 Frequency and ranking of related factors for family doctor contracted services from the perspective of consumers

\begin{tabular}{ll}
\hline Sequence & Factor \\
\hline 1 & National government factors \\
2 & Contract doctor- related factors \\
3 & Community health service agency factors \\
4 & Consumers-related factors \\
\hline
\end{tabular}

doctors should be included in the scope of medical insurance. CFDS should be linked with medical insurance, facilitating family doctors' gatekeeper role in terms of medical insurance control fees and health management.

The results demonstrated that the community health service institutions factor is also one of the related CFDS factors. The community health service agency is the executor of the contracted service's policy, and the extent of its power of execution directly determines the direction of CFDS, and the completeness of the hardware and software facilities of a community health service organization is the basis of its power of execution. Therefore, the degree of development of its informatization, medical facilities, and equipment within the institution, and performance assessment and incentive mechanisms are all necessary conditions for the promotion of contracted services. At the same time, the supporting hardware facilities of the community health service institutions, including equipment and drugs are insufficient, which impedes the development of CFDS. However, family doctor team members, as important stakeholders of the medical alliance, can mobilize their enthusiasm and achieve the sustainable development of contracted services only if they are allowed to obtain reasonable benefits from contracted service operations [39]. Therefore, some suggestions are necessary from the perspective of community health institutions. First, community health institutions should speed up the development of a unified information platform to achieve dynamic management of contracted patients'/consumers' information and the analysis of the dynamics of consumers through real-time data monitoring. At the same time, community health agencies should increase investment in hardware facilities, thereby making medical services more accessible to patients/consumers, changing their views on primary medical care and increasing satisfaction with primary health services [38]. The most important point is that salary not only meets the basic survival needs of employees, but also is a kind of recognizing and respecting employee performance and contributions [40]. Therefore, community health agencies should establish a sound supporting performance appraisal system and incentive mechanism, to increase employees' enthusiasm toward their work, helping them better serve patients/consumers.
Consumer-related factors have a great impact on contracted services. As important stakeholders involved in the reform of China's health care and CFDS, patients/ consumers are mainly concerned with medical technology, medical expenses, emotional support, and respect. With the development of the medical system and the improvements in its economic development, patients/ consumers' demands for overall medical services have been increasingly met, and service quality is a key factor in attracting patients/consumers. The results of the survey and interviews suggest that patients/consumers are not confident about the qualifications and medical technology of family doctors and community health agencies. The government must create an atmosphere of public opinion that understands and supports the services of family doctors, and reasonable contracting fees need to be formulated. We also recommend that residents respect, support, and cooperate with family doctors.

Factors related to contracted doctors also influence CFDS. Family doctors and team members are the flagbearers of CFDS, and their service capabilities, willingness, and attitudes all influence its smooth development. According to the 'Guiding Opinions of the State Council on Establishing the General Practitioner System', training qualified family doctors by vigorously carrying out transfer training for community doctors and raising the academic qualification level of community doctors can also reduce the workload of existing family doctors and teams, thus providing more effective health care. Moreover, community health organizations should strengthen the talent team construction of family doctors in all aspects, conduct regular training for family doctor teams, and attract graduates of general medicine or specialists in second and third-level hospitals who have undergone standardized training. In addition, the service quality of community health service centres and the level of medical technology should be improved. This will increase patients/consumers' sense of identity and belonging, and improve their satisfaction. At the time of diagnosis, the team of family doctors should pay attention to service attitude, reduce the distance between themselves and patients, and provide humanistic care.

\section{Limitations}

This study has two limitations. First, the sample size of the study was small; a typical survey needs to select a sample representative of a typical unit, so the researchers need to exercise particularly good judgement, or their conclusions may be biased, and it may be difficult to generalise from the results of a typical survey to the overall situation. Second, differences in self-perception between medical staff and patients may have biased their responses, affecting the outcomes. Future research can further improve the overall design and reduce the 
impact of cognitive differences on outcomes. Third, this study only refines several related factors but did not indicate the mechanism of which factor worked.

\section{Conclusions}

National governments, community health agencies, community health workers, and consumers play an important role in the advancement of CFDS. Therefore, the development of CFDS needs to consider the rights and interests of all stakeholders involved.

\section{Supplementary information}

Supplementary information accompanies this paper at https://doi.org/10. 1186/s12913-019-4801-y.

Additional file 1: Questionnaire S1. Influencing factors of contracted services of family doctors.

Additional file 2: Table S1. Explained total variance.

\section{Abbreviations}

CFDS: Contracted Family Doctors Services; CFI: Comparative fit index; GFI: Goodness of fit index; NFI: Normed fit index; RMR: Root mean square residual; RMSEA: Root mean square error of approximation; TLI: Tucker-Lewis incremental fit

\section{Acknowledgments}

The authors would like to give their sincere thanks to all participants who had helped collect data and distribute questionnaires.

\section{Authors' contributions}

HW, LS, XH and LF conducted calculations, analyzed results, and drafted the manuscript. HW, LS, JZ, LF and FL were responsible for the overall design of the research, organized and conducted the survey, and designed the analyses framework. HW, LS, XH, YM, XY, ML and FL revised the paper. HW, LS, JZ, YM, XY and $\mathrm{ML}$ assisted with the literature review and data collection. All authors approval of the current version of this manuscript for publications.

\section{Funding}

This study was funded by the Department Grass-roots Health, National Health and Family Planning Commission of the People's Republic of China, the National Natural Science Foundation of China $(71603066,71473063)$ and also was funded by the Innovative Research Projects of Graduate Students at Harbin Medical University (YJSCX2017-15HYD). The funding body did not have any role in the design of the study, data collection, analysis, interpretation of data, or drafting of the manuscript.

\section{Availability of data and materials}

The datasets used and/or analysed during the current study are available from the corresponding author on reasonable request.

\section{Ethics approval and consent to participate}

This research project was approved by the Medical Ethics Committee of Harbin Medical University. We obtained approval from the community health centre. We received approval from the community health centre, and also obtained the consent of all participants and signed an informed consent form.

\section{Consent for publication}

Not applicable.

\section{Competing interests}

The authors declare that they have no competing interests.

\section{Author details}

${ }^{1}$ Department of Health Management, School of Health Management, Harbin Medical University, No.157 Baojian Road, Nangang District, Harbin 150081,
China. ${ }^{2}$ Human Resource Office, Women's Hospital School of Medicine, Zhejiang University, Hangzhou, Zhejiang, China. ${ }^{3}$ Department of Neurosurgery, The Second Affiliated Hospital of Harbin Medical University, Harbin, Heilongjiang, China. ${ }^{4}$ Department of Medical Dispute, Maternal and Child Health Hospital, Heyuan, Guangdong, China. ${ }^{5}$ Department of Public Health Research, School of Public Health, Qiqihar Medical University, Qiqihar, Heilongjiang, China.

Received: 25 August 2019 Accepted: 2 December 2019

Published online: 21 December 2019

\section{References}

1. Declaration of Alma-Ata. http://www.euro.who.int/en/publications/ policydocuments/declaration-of-alma-ata, 1978.

2. Dupuits FM, Hasman A, Pop P. Computer-based assistance in family medicine. Comput Methods Prog Biomed. 1998;55(1):201-3.

3. Kidd M. The Contribution of Family Medicine to Improving Health Systems: A Guidebook from the World Organization of Family Doctors[C]// Acm Symposium on User Interface Software \& Technology. ACM, 2013.

4. Du XL. Research on family doctor system implemented in Shanghai. Shanghai Jiaotong Univ. 2012.

5. Bindman $A B$, Majeed $A$. Primary care in the United States: organisation of primary care in the United States. BMJ. 2003;326:631-4.

6. Avery DM Jr, Hooper DE, McDonald JT Jr, Love MW, Tucker MT, Parton JM. The economic impact of rural family physicians practicing obstetrics. J Am Board Fam Med. 2014:27(5):602-10.

7. Seehusen DA, Bowman MA, Neale A. Context and trade-offs in family medicine. J Am Board Fam Med. 2014;27(4):433-6.

8. Zheng $\mathrm{FH}, \mathrm{Wu} \mathrm{XN}$. Cuban health practice inspiration for a new round of health reform in China. Med Soc. 2008;6:30-1.

9. Dobson R. Danish men consult gps less than women but attend hospital more and have greater mortality. BMJ. 2007;335(7628):1010-1.

10. Xinhua News Agency. Opinions of the State Council of the Central Committee of the Communist Party of China on Deepening the Reform of Medical and Health System. http://www.gov.cn/jrzg/2009-04/06/content_12 78721.htm. Accessed 26 Sept 2019

11. The State Council. Guidance of the State Council on the Establishment of a General Practitioner System. http://www.nhfpc.gov.cn/tigs/s358-1/201107/01 b165abaf3d4e7ea5 6acb 0e f6b00779. shtml. Accessed 26 Sept 2019.

12. Circular on the issuance of guidance on promoting contracted family doctor service. http://www.nhfpc.gov.cn/tigs/s3577/20106/e3e7d2670a8b41 b1fe8e409c7887af.Shtml. Access ed 26 Sept 2019.

13. General Office of the National Health Commission of the People's Republic of China. Circular on the contracted family doctor service in 2018. http:// www.nhfpc.gov.cn/jws/s3581r/2018 04 /a3dfc6bfa9774 c27bdc86b2-a03 83467d.shtml. Accessed 26 Sept 2019.

14. Liu S, Wang L, Zhang T, Liu C, Liang H, Zhang Y, et al. Factors affecting the work competency and stability of family doctors in Shanghai: a tracking study. BMC Fam Pract. 2019;20(1):95.

15. Liu YY, Fan ZZ, Yao DM. A comparative study of family doctors' contracting service model based on rainbow model. Health Econ Res. 2019;3(36):26-8.

16. Ling S, Ning XU. Analysis of problems in the process of contracting services with community doctors team under integrated medical treatment and nursing care system and corresponding countermeasures. Chin Gen Pract. 2017;20(33):4096-9.

17. Yang SY, Chen L. Chronic diseases first, co-management of doctors of three kinds and reform of hierarchic diagnosis and treatment benefiting masses of people. Mod Hosp Manage. 2016;4(14):2-6.

18. Huang J, Liang $H$, Zhang $Y$, Wang $X$, Zhang W, Zhang J, et al. Promotion the localizaiton dilemma and strategy for the family doctor system: a case study of Hongkou District, Shanghai. Chin J Health Policy. 2016;8(9):37-43.

19. Liang $H, H e X$. The Changning model in the exploration and reform of Chinese family doctor system. Chin J Health Policy. 2018;10(10):1-2.

20. Huang J, Fang S, Liang H, Liu S, Wang L. Effect of the collaborative reform of family doctor contract service on residents' health management. Chin Heal Res. 2018:4:329-41.

21. Huang J, Gao Z. Health management and effect analysis of family doctor system: a case study from Changning District of Shanghai. China Health Insur. 2017:2:33-6.

22. Hou J, Lu J, Qiao L. Exploration of implementing contractual service relationship between family doctor and residents in rural communities. Chin Gen Pract. 2014;3(28):7-9. 
23. Huang J, Liu S, He R, Fang S, Lu W, Wu J, et al. Factors associated with residents' contract behavior with family doctors in community health service centers: a longitudinal survey from China. PLoS One. 2018;13(11): e0208200.

24. Tao W, Zeng W, Yan L, Yang H, Wen J, Li W. The health service capacity of primary health care in West China: different perspectives of physicians and their patients. BMC Health Serv Res. 2019;19(1):143.

25. Shang X, Huang Y, Li B, Yang Q, Zhao Y, Wang W, et al. Residents' awareness of family doctor contract services, status of contract with a family doctor, and contract service needs in Zhejiang Province, China: a crosssectional study. Int J Environ Res Public Health. 2019;16(18):E3312.

26. Lu P, Zhu J, Jin MJ, Weng LL, Liu ML. Standardized construction of studio of family physicians and it service effectiveness. Chin Gen Pract. 2016;19(31): 3776-80.

27. Gu J, Zhen T, Song Y, Xu L. Job satisfaction of certified primary care physicians in rural Shandong Province, China: a cross-sectional study. BMC Health Serv Res. 2019;19(1):75.

28. Li L, Zhong C, Mei J, Liang Y, Li L, Kuang L. Effect of family practice contract services on the quality of primary care in Guangzhou, China: a crosssectional study using PCAT-AE. BMJ Open. 2018;8(11):e021317.

29. Niu Y, Zhang L, Ye T, Yan Y, Zhang Y. Can unsuccessful treatment in primary medical institutions influence patients' choice? A retrospective cluster sample study from China. BMJ Open. 2019;9(1):e022304.

30. Luo D, Yang WX, Han C. Study on the degree of professional satisfaction of general practitioners in TianJin and its influencing factors. Chin Gen Pract. 2015;18:2701-4

31. Fu W, Zhao S, Zhang Y, Chai P, Goss J. Research in health policy making in China: out-of-pocket payments in healthy China 2030. BMJ. 2018;360:k234.

32. The State Council. China to improve health services for seniors. China to improve health services for seniors. http://english.www.gov.cn/statecouncil/ ministries/201908/01/conte nt_WS5 d422c86c6d0c6695ff7e086.html. Accessed 26 Aug 2019

33. National Health Commission of the People's Republic of China. a circular on finish contracted family doctors service in 2019. http://www.gov.cn/ xinwen/2019-04/30/con tent5387891.htm. Accessed 26 Aug 2019.

34. Gaojie Xu, Yingying Hu, Xi Yang, Zhijia Tu, Song Li, Lin Chen. Research on the Utilization of Family Doctor Contraa Service and Its Influencing Factors in Dongming Community of Pudong New Area. Chinese Primary Health Care. 2016;30(9):11-3.

35. Lu W. The policy practice of Changning family doctor system and its impact analysis. Fu Dan Univ. 2014.

36. Zhou C, Mou H, Xu W, Li Z, Liu X, Shi L, et al. Study on factors inducing workplace violence in Chinese hospitals based on the broken window theory: a cross-sectional study [J]. BMJ Open. 2017;7(7):e016290.

37. Shi L, Fan L, Xiao H, Chen Z, Tong X, Liu M, et al. Constructing a general competency model for Chinese public health physicians: a qualitative and quantitative study. Eur J Pub Health. 2019. https://doi.org/10.1093/eurpub/ ckz048.

38. Li X, Lu J, Hu S, Cheng KK, De Maeseneer J, Meng Q, et al. The primary health-care system in China. Lancet. 2017:390(10112):2584-94.

39. Chi MH, Shang J, Sun T. Problem identification and analysis of regional medical consortium under ROCCIPI framework. Chin Hosp Manage. 2014;34: 19-21.

40. Manca D, Varnhagen S, Brett-MacLean P, Allan GM, Szafran O. Respect from specialists: concerns of family physicians. Can Fam Physician. 2008;54(10): $1434-5$

\section{Publisher's Note}

Springer Nature remains neutral with regard to jurisdictional claims in published maps and institutional affiliations.

Ready to submit your research? Choose BMC and benefit from:

- fast, convenient online submission

- thorough peer review by experienced researchers in your field

- rapid publication on acceptance

- support for research data, including large and complex data types

- gold Open Access which fosters wider collaboration and increased citations

- maximum visibility for your research: over $100 \mathrm{M}$ website views per year

At BMC, research is always in progress.

Learn more biomedcentral.com/submissions 